\title{
Novos desafios à privacidade: os círculos sociais e as redes sociais (social networks)
}

\section{The new challenges to privacy: social networks}

\author{
Seiiti Arata Jr(1)
}

Arata Jr S. Novos desafios à privacidade: os círculos sociais e as redes sociais (social networks). Saúde, Ética \& Justiça, São Paulo. 2003;8(1/2):44-56.

RESUMO: Os websites de redes sociais (social networks) despertaram grande curiosidade e entusiasmo do mercado brasileiro a partir do ano de 2004. São apresentadas neste estudo breves reflexões acerca da relação entre a estrutura tecnológica e termos de uso implementados e seus efeitos jurídicos sobre a privacidade. A noção de privacidade é historicamente desenvolvida conforme novas tecnologias ameaçam as antigas expectativas de relacionamento social dos indivíduos, e das respostas tecnológicas, éticas e jurídicas que se apresentam. As redes sociais eletrônicas permitem uma integração de diversos círculos sociais inédita, dificultando o tradicional uso de máscaras sociais e separação de informações dentro de determinados contextos. Em algumas situações essa característica pode significar uma ameaça à intimidade, o que deve ser objeto de abordagens jurídicas e tecnológicas. Independente da escolha adotada, o que se deve ter em mente é a subjetividade da noção de verdade, privacidade, intimidade. E que as soluções não devem engessar ou impor níveis arbitrários, mas sim proteger aqueles que buscam um maior resguardo de suas informações ao mesmo tempo que sejam implementados eficientes mecanismos de comunicação que permitam aqueles que buscam expressar-se de forma mais ampla.

DESCRITORES: Privacidade. Confiabilidade da tecnologia.

\footnotetext{
(1) Advogado especializado em assuntos ligados à indústria da tecnologia da informação e comunicação. Graduado em Direito pela Universidade de São Paulo - USP, em 2001. Mestrando em Direito Internacional pela Universidade de São Paulo - USP. Ex-Pesquisador da Fundação de Amparo à Pesquisa do Estado de São Paulo - FAPESP (1998-1999). Membro da Comissão Especial de Informática Jurídica da Ordem dos Advogados do Brasil - Secção São Paulo. Autor de artigos jurídicos premiados em competições internacionais no Brasil, Alemanha, Suíça e China.
}

Endereço para correspondência: Rua Dr. Eduardo de Souza Aranha, 387 - 15ํandar. Vila Nova Conceição. CEP: 04543-121, São Paulo - SP. e-mail: saj@bluemail.ch 


\section{A dramaturgia da persona}

A palavra latina persona, composta pelo prefixo per (por, através) e sufixo sono (som), era usada originalmente como referência à máscara usada pelos atores nas representações teatrais. Em seu "Vocabulário Jurídico", De Plácido e Silva observa a conexão da persona com a expressão "dramatis personae", alusão aos representantes ou personagens dramáticos, isto é, os próprios atores ${ }^{[1]}$.

Essa análise etimológica revela uma noção teatral relacionada à idéia de pessoa que é constantemente explorada pelas artes e ciências humanas. Abordando a evolução histórica do conceito de pessoa humana, Comparato ${ }^{7}$, identifica o estoicismo como o primeiro marco na elaboração teórica do conceito de pessoa, em que a persona teatral (o papel exercido pelos indivíduos em relações sociais) é separada da essência individual de cada ser humano (que passa a ser denominada personalidade), de modo que o papel dramático que cada um de nós representa na vida não se confunde com a individualidade pessoal (p.16).

O conceito dramaturgo de persona é também desenvolvido em The Presentation of Self in Everyday Life ${ }^{[2]}$ do sociólogo canadense Erving Goffman, que defende que quando um indivíduo está na presença de outros, estes outros procuram obter informações a seu respeito e também trazer à discussão elementos de informação que já possuam sobre ele. A interação é vista como uma performance moldada de acordo com a audiência e ambiente social cujo script busca transmitir impressões coerentes com os objetivos dos atores. A atuação independe do estado mental do indivíduo de modo que a persona teatral ocorre independente de sua vontade consciente em realizar a performance.

Resumidamente, as informações necessárias para a atuação podem ser obtidas através de duas formas: aquelas verbalmente fornecidas e aquelas expressas de modo contextual, não verbal, não intencional. $\mathrm{O}$ indivíduo busca o controle sobre a conduta alheia no que toca à sua pessoa; esse controle é obtido por uma mudança em seu próprio comportamento de modo a transmitir uma impressão que faça com que os outros ajam de acordo com seus planos e para apresentar uma versão idealizada de si que seja mais consistente com as normas sociais, comparativamente com seu comportamento quando não está diante de uma audiência. Esse uso da persona como máscara define o palco de uma peça de infinitos atos de falsas revelações e subterfúgios até que um determinado consenso seja atingido.

As atuações sofrem invariavelmente o efeito da segregação de audiências, de modo que performances específicas são feitas para determinadas platéias, conforme suas expectativas. A espontaneidade, nesse processo, é fundamental para que não seja transmitida uma impressão artificial do comportamento.

\section{Viver na verdade: a multiplicidade de opiniões}

Goffman reconhece que existem diferenças culturais na representação do eu, ao reportar que membros de uma cultura anglo-americana têm a tendência de viver vidas sociais enclausuradas, interagir em ambientes determinados, manter estranhos à distância, dar aos atores uma certa privacidade para que realizem seu show e, em geral, compartilham uma seriedade e união quanto aos dramas cívicos comuns. Estudos semelhantes são desenvolvidos nos mais diversos contextos; no Brasil merece destaque o magistral estudo sobre o povo brasileiro feito por Sérgio Buarque de Holanda, em Raízes do Brasil, que apresenta o conceito do "homem cordial", cuja intimidade marca uma indistinção entre o público e o privado e todos são amigos em todos os lugares ${ }^{[3]}$.

\footnotetext{
[1] Os romanos usavam o termo persona com significado geral de ser humano, independentemente de sua condição como pessoa física, sujeito de direito, ou de sua condição como escravo, objeto de direito.

${ }^{[2]}$ Apesar de rica, esta obra não apresenta uma descrição completa do processo interativo. A natureza de indivíduos marginalizados, a importância do ritual e cerimônia na dramaturgia e na construção de personagens é aperfeiçoada em outras obras posteriores de Goffman, como Stigma e Interaction Ritual.

${ }^{[3]}$ As idéias de Sérgio Buarque de Holanda contribuem também para a compreensão do grande sucesso de software sociais entre brasileiros, como o Fotolog, Orkut, Multiply, entre outros, cujas estatísticas demonstram que o Brasil lidera em quantidade de usuários cadastrados. A análise cultural também explica a menor preocupação do ordenamento jurídico brasileiro com questões ligadas à privacidade e liberdade de expressão, que ganham cunho mais severo nos Estados Unidos da América. Apesar das diferenças entre os sistemas jurídicos, valemo-nos no presente estudo da doutrina e experiência americana na definição da problemática relacionada à privacidade e soluções propostas, com as devidas ressalvas na análise do direito comparado.
} 
Entretanto, independentemente destes comportamentos geralmente compartilhados em uma determinada coletividade, existe uma multiplicidade de opiniões que os indivíduos podem tomar diante da questão de como ser espontâneo e verdadeiro. A dificuldade da comunhão de opiniões e mesmo da mútua compreensão quando as vidas das pessoas já estão bem definidas e construídas com base em diferentes experiências é bem ilustrada em " $A$ Insustentável Leveza do Ser"12. Kundera ${ }^{12}$ dedica a terceira parte de sua obra para As palavras incompreendidas entre Sabina e Franz, elaborando um léxico de noções opostas sobre diversos temas, das quais a publicidade e a privacidade são assim tratadas:

\section{"VIVER NA VERDADE}

É uma fórmula que Kafka usou em seu diário ou numa carta. Franz não se lembra bem. Está seduzido por essa fórmula. $\mathrm{O}$ que era viver na verdade? Uma definição negativa é fácil: é não mentir, não se esconder, não dissimular nada. Desde que conheceu Sabina, vive na mentira. Conversa com sua mulher sobre congressos em Amsterdam, e conferências em Madri que jamais aconteceram, tem medo de passear com Sabina nas ruas de Genebra. Acha divertido mentir e se esconder, justamente porque nunca o fez antes. Sente o prazer de um primeiro da classe que decide um dia, finalmente, cabular.

Para Sabina, viver na verdade, não mentir nem para si nem para os outros, só é possível se vivermos sem público. Havendo uma única testemunha de nossos atos, adaptamo-nos de um jeito ou de outro aos olhos que nos observam, e nada mais do que fazemos é verdadeiro. Ter um público, pensar num público, é viver na mentira. Sabina despreza a literatura em que o autor revela toda a sua intimidade, e também a de seus amigos. Quem perde sua intimidade perde tudo, pensa Sabina. E quem a ela renuncia conscientemente é um monstro. Por isso, Sabina não sofre por ter que esconder seu amor. Ao contrário, para ela esta é a única forma de viver 'na verdade'

Quanto a Franz, está convencido de que na separação da vida em domínio privado e em domínio público está a fonte de toda mentira: a gente é uma pessoa em particular e outra em público. Para Franz, viver 'na verdade' é abolir a barreira entre o privado e o público. Mencionava com prazer a frase de André Breton em que ele dizia que gostaria de viver 'numa casa de vidro' onde nada é segredo e que está aberta a todos os olhares" (p.133)'

Através de seus personagens, Kundera ${ }^{13}$ trabalha uma de suas principais preocupações, a luta pela defesa de seu direito à vida íntima. Para ele existe uma fronteira mística entre a vida íntima e a pública que não se pode atravessar impunemente ${ }^{[4]}$.

\section{Enfraquecimento da fronteira entre o público e o privado}

A divisão entre a vida pública e a privada, porém, cada vez torna-se mais tênue conforme são difusas as novas tecnologias de computação e as inovações multimídia de comunicação que aumentam as conexões entre locais e pessoas que estavam anteriormente isolados, num processo de virtualização ${ }^{[5] 15}$. Como resultado, o indivíduo já não mais pode confiar em seus sentidos na determinação de que tipo de ambiente ele se encontra para o uso da persona como a máscara de Goffman ${ }^{[6]}$. Ademais, o indivíduo perdeu significativa parte de seu controle sobre a noção de estar sendo observado, ouvido e mesmo filmado. O espaço físico percebido ao redor do indivíduo não é mais um indicador dos locais ou pessoas que possam estar a ele conexos. Assim, locais que parecem privados, podem ser públicos.

A fixação da fronteira entre o público e o privado dentro de uma perspectiva liberal para compatibilizar

\footnotetext{
${ }^{[4]}$ Em "Testaments betrayed: an essay in nine parts", Milan Kundera ${ }^{23}$ diz que apenas um hipócrita afirmaria que, por inexistir tal fronteira, vive a mesma pessoa tanto na vida pública como na íntima. Aqueles que assim o fazem seriam monstruosos, acabando por abdicar de espontaneidade na sua vida íntima e agindo de modo irresponsável na vida pública. Kundera posiciona-se de modo diametralmente oposto a Kant, para quem o mal é, por definição, secreto e que o moral é aquilo que é apto a ser visto, de modo que a moralidade se traduz exatamente na coincidência entre o público e o privado.

[5]Pierre Lévy em "O que é o Virtual?", define o processo de virtualização como uma "heterogênese, um devir outro, processo de acolhimento da alteridade", sendo que o "virtual" não é oposto a "real". O "virtual" está oposto ao "atual": enquanto a atualização é a solução de um problema não anunciado, uma produção de novas qualidades, a virtualização é seu movimento inverso, uma "elevação à potência" da entidade considerada

${ }^{[6]} \mathrm{O}$ tema da construção da subjetividade é tratado por inúmeros teóricos que dedicaram estudos sobre este complexo assunto. Goffman é escolhido para o presente estudo como o autor mais apropriado para identificar a problemática da harmonização das relações em redes sociais que conectam diversos círculos sociais. Para referências em outras searas da subjetividade, pode-se recorrer a René Descartes, Jean-Jacques Rousseau, Michel Foucault, Gilles Deleuze, David Hume, Lev Vygotsky, Mikhail Bakhtin, Anthony Giddens, George Berkeley, entre outros.
} 
a liberdade de mercado, o controle da informação e a proteção da privacidade é o paradoxo da liberdade (p.17) $)^{16}$, de difícil equilíbrio.

Arendt ${ }^{7}$ discorre com detalhes o surgimento $e$ evolução dos conceitos de "público" e "privado", indicando que o individualismo moderno contribui para o enriquecimento da esfera privada que, inicialmente, indicava que o indivíduo assim estaria privado das mais dignas capacidades do homem que eram exercidas nos negócios da res publica. Existem algumas informações que devem ser ocultadas e outras que devem ser expostas em público para que possam adquirir alguma forma de existência. Para ela a distinção é necessária pois somente longe da luz do espaço público a vida íntima é possível.

Quando as duas esferas são claramente distintas, é possível comportar-se conforme as expectativas e necessidades sociais. Quando as esferas se entrelaçam ${ }^{[7]}$, isso fica mais difícil e existe uma tendência à retração comportamental e menor interação social ou então em um comportamento inconseqüente e sujeito a erros não seriam cometidos se os indivíduos estivessem em um ambiente mais claro.

\section{Círculos sociais}

Paralela e complementarmente à visão dual público/privado, para compreender os fenômenos sociais é útil a identificação de círculos sociais, nos quais determinadas informações sobre o indivíduo podem estar mais públicas do que outras. Cada um dos círculos sociais compartilha, genericamente, de um ponto de vista de nossa individualidade projetada. A multiplicidade de círculos sociais é assim tratada por Pontes de Miranda ${ }^{20}$ :

"O fato social é a relação de adaptação (ato, combinação, fórmula) do indivíduo à vida social, a uma, duas ou mais coletividades (círculos sociais) de que faça parte, ou dessas aos indivíduos, entre si. Tais círculos, pré-histórica e históricamente, foram o par, o clã, a fratria, a família, a tribo, a nação de tribos, etc. Na mesma época, podem ser, quanto à extensão: o par sexual, a amizade, a família, a escola, a classe social, o partido, o bairro, o Município, o Estado-membro, o Estado, etc" (p.37).

Sobre o tratamento jurídico dessa multiplicidade de círculos sociais, o clássico autor aponta que em tempos de evolução social é necessária uma referência à sociologia, em particular à lei da crescente dilatação e integração dos círculos sociais.

\section{Integrando os círculos sociais: as redes}

As redes sociais são formadas por grupos de pessoas conectadas através de distintas formas $\mathrm{e}$ graus de familiaridade. Têm sido objeto de numerosos estudos de sociologia e antropologia. Seu estudo matemático é feito através da teoria dos grafos, que representa objetos através de vértices e elos que possibilitam atribuir valores quantitativos às redes sociais e assim melhor interpretar como os indivíduos interagem em situações complexas, como epidemias virais, organizações terroristas e contatos potenciais para o sucesso profissional. Através de sistemas de reputação que podem ser construídos a partir de redes sociais, é também vislumbrada uma solução técnica para melhor filtragem de $\mathrm{spam}^{9}$. Apesar da utilidade das diversas aplicações práticas com finalidade de aperfeiçoamento de mercado e redução de custos de transação, sua utilização deve ter em mente os riscos de violações ao direito à privacidade, direito à imagem e abusos na manipulação de bancos de dados, entre outros que serão brevemente abordados neste estudo.

As redes, quando bem utilizadas, permitem que o homem alcance objetivos antes remotos ${ }^{[8]}(p .10) \mathrm{e}$ otimize as suas relações de oferta e demanda ${ }^{24}$. Nesse sentido, é extremamente positiva para a efetivação da Declaração de Princípios e do Plano de Ação traçados pela Cúpula Mundial sobre a

\footnotetext{
${ }^{[7]}$ Ou mesmo quando o espaço público deixa de ser geograficamente definido (como era a Ágora ateniense) e a pauta dos debates passa a ser definida pela mídia. Maiores considerações sobre as transformações do espaço público são desenvolvidas por Habermas em $A$ Transformação Estrutural da Esfera Pública. Celso Lafer, em A Reconstrução dos Direitos Humanos: um diálogo com o pensamento de Hannah Arendt, São Paulo, Companhia das Letras, 2001, aponta para a crescente interferência na esfera da vida privada por parte do poder público e uma maior possibilidade de terceiros se intrometerem no âmbito da intimidade das pessoas. Observa-se que não se trata de um fenômeno de uma via apenas: a discussão e exposição das intimidades ao domínio público trivializam a bisbilhotice e banalizam o público.

${ }^{[8]}$ As redes de movimentos sociais, por exemplo, potencializam a força discurso político e de articulação "entre o local e o global, entre o particular e o universal, entre o uno e o diverso, nas interconexões das identidades dos atores com o pluralismo", observa Scherer-Warren ${ }^{41}$ em Redes de movimentos sociais.
} 
Sociedade da Informação ${ }^{34}$. Como toda tecnologia, porém, os seus usuários devem ser suficientemente educados para utilizar as novas ferramentas da melhor forma possível e evitar situações que possam implicar em riscos morais e patrimoniais.

\section{As redes sociais no ciberespaço}

Através da Internet as redes sociais ganham eficiência e possibilitam diversas aplicações pela facilidade em cruzamento de bancos de dados. Tornaram-se uma grande sensação a partir de 2003 com a popularidade de certos websites ${ }^{[9]}$. Assim como os primeiros estudos feitos sobre o ciberespaço freqüentemente faziam referência à obra Neuromancerdo escritor de ficção cyberpunkWilliam Gibson, os recentes escritos feitos acerca das redes sociais na Internet fazem invariavelmente alusão à expressão "seis graus de separação[ ${ }^{[10]}$, associada ao Small World Experiment de Stanley Milgram, que mostra que os círculos sociais estão muito próximos uns dos outros e muitas vezes com amplas áreas de intersecção. Deste modo, a atuação da persona deve, cada vez mais, adequar-se a mais de uma platéia simultaneamente.

Apesar do sucesso em angariar grande número de usuários utilizando marketing viral e interface popular, conectando os indivíduos a seus diversos círculos sociais, é possível defender que as redes sociais não são inovadoras ${ }^{[11]}$, pois, desde os primórdios da comunicação digital em rede, diferentes plataformas foram disponibilizadas para relacionamentos, seja através dos bulletin board services, Usenet, multi-user dungeons, internet relay chat, WELL, usenet, home pages, websites de serviços de recolocação profissional, namoros, fóruns de discussão diversos, weblogs, fotologs, wikis... de modo que a nova geração de redes sociais não é arauto do conceito de social software ${ }^{27}$.

Independente dos questionamentos que possam ser feitos acerca da novidade na técnica de comunicação, é fato que as redes sociais na Internet conquistaram popularidade a partir de 2003. São tecnologias pautadas por uma série de valores e conseqüências, algumas previstas e outras inesperadas. É o primeiro princípio do tecnorrealismo ${ }^{30}$ : as tecnologias não são neutras. Cada um destes possui valores diferentes, e devem atentar para determinados riscos jurídicos, principalmente aqueles advindos das novas formas de interação social acima descritas. Cada um dos meios de comunicação é reflexo de uma tecnologia sendo adaptada para permitir uma interação social e uma apresentação do eu social e consciente.

O meio pelo qual os indivíduos se conectam digitalmente é, porém, tão distinto do mundo físico que os comportamentos sociais tendem a ser diferentes: a tecnologia não apenas conecta as pessoas, mas define como elas interagem. O meio é a mensagem. Assim, cumpre analisar como cada manifestação de rede social lida com a frágil redoma da intimidade. Cada uma delas é pautada com diferentes valores e objetivos. Nesse sentido, Heyman ${ }^{10}$, em "Distributed social network protocol" diz que a informação fornecida nas redes sociais varia conforme a premissa do serviço oferecido. Heyman ${ }^{19}$ classifica algumas redes sociais que implicitamente postulam que os amigos de amigos podem ser potenciais amigos ou parceiros românticos, e outros que postulam que os amigos de amigos são mais tendenciosos da dar confiança ao indivíduo, facilitando sua inserção profissional.

A escolha em focar em um determinado círculo social é meramente opção tecnológica e estratégica do plano de negócios daquele que disponibiliza os serviços de uma rede social. Existem projetos que integram diversos círculos simultaneamente. Isso pode tanto estimular contatos não óbvios (colegas de trabalho deparando-se com informações acerca da intimidade tradicionalmente familiar) como

\footnotetext{
[9] Segundo matéria de David Pescovitz intitulada "The technology of the year: social network applications", dentre os projetos mais populares pode-se destacar o SixDegrees.com, fundado em 1997 e com atividades encerradas em 2000. Posteriormente, Ryze, eCademy, Spoke Software e Linkedln para networking profissional, Friendster com foco em relacionamentos românticos, Visible Path focado em comércio, e Tribe.net e Orkut, versões beta, congregando distintos usos simultâneos. No Brasil, destaca-se o $1 \mathrm{Grau}$.

[10] Postulado de que qualquer indivíduo estaria conectado a qualquer outro no mundo através de uma pequena seqüência (seis intermediários) de conhecidos, o que é parcialmente explicado pela existência de hubs, pessoas que têm uma vasta rede de contatos e aproximam diferentes grupos.

${ }^{[11]} \mathrm{O}$ professor da New York University, Clay Shirky, inclui em sua definição de software social todo o tipo de software que permita comunicação coletiva, desde o campo "c.c." no email até vastos mundos virtuais como o de EverQuest, podendo ser não-direcionados como uma sala de bate papo ou visando uma determinada tarefa, como um wiki.
} 
também gerar conflitos, pois as informações que a persona busca representar não encontram mais os limites tradicionais e são distribuídas a todos os membros de todos os círculos sociais indistintamente.

\section{Forças regulatórias}

Considerando-se que as tecnologias implicam sempre em uma série de efeitos, tanto positivos quanto negativos ${ }^{21}$, é fundamental analisar quais são os valores que orientam uma determinada tecnologia para a análise dos efeitos que esta pode causar através de sua adoção. Lessig ${ }^{14}$, em "Code and other laws of cyberspace", lidera forte corrente doutrinária próxima da "Teoria tridimensional do direito" Reale ${ }^{22}$, que postula que o "Direito é uma integração normativa de fatos segundo valores ${ }^{[12]}$. A teoria Code is Law de Lessig $^{14}$ dá forte ênfase a essa dimensão tecnológica (fática) pela sua força regulatória que interage com a força jurídica.

Valendo-se de observações de David Chaum, Agre $^{1}$ relata que registros de dados não podem causar problemas de privacidade se a base tecnológica não permitir sua atribuição aos indivíduos cujas vidas representam (p.52). Caso os bancos de dados identifiquem os indivíduos através de métodos universais como nome ou número de documento de identidade, os dados podem ser facilmente propagados e cruzados, e assim empregados para finalidades secundárias em detrimento do indivíduo. Assim, Chaum apresenta a abordagem alternativa de empregar pseudônimos digitais. Entretanto, a coleta de dados de uma rede social verdadeira ${ }^{[13]}$ é justamente oposta à de um sistema que protege a privacidade usando pseudônimos.

A inexistência de um sistema seguro permite, tecnologicamente, que dados falsos sejam lançados ao sistema, encontra-se, desde as primeiras manifestações de comunicações digitais, homens passando-se por mulheres, crianças por adultos, em uma insegurança de comunicação que ficou marcada pela frase "Na Internet ninguém sabe que você é um

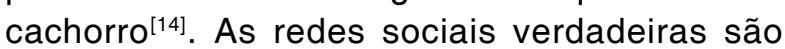
prejudicadas pela ausência de sistemas seguros que não permitem evitar que falsos perfis sejam inseridos, representando personagens de ficção literária, cinematográfica ou mesmo pessoas reais diferentes daquelas que criaram o perfil virtual. Os falsos perfis permitem aplicações inovadoras ${ }^{[15]}$, porém apresentam riscos de infração à propriedade intelectual, calúnia, difamação, injúria, falsidade ideológica, entre outras infrações jurídicas que diminuem a confiança no sistema e portanto seu funcionamento otimizado.

Observa-se que parte dos problemas encontrados nas interações em redes sociais verdadeiras ocorre pelas diferentes expectativas que cada um dos usuários tem sobre o sistema, o que é reduzido em casos de redes sociais que utilizam pseudônimos ou são focadas para determinadas aplicações, como os jogos interativos, namoros, busca de emprego... e assim evitam a colisão de diferentes círculos sociais. Para lidar com as múltiplas necessidades e expectativas dos usuários de uma

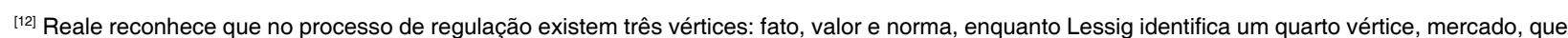
pode ser compreendido como uma manifestação fática. Assim, as decisões comportamentais ponderam a influência exercida por cada um destes vértices, de modo a prosseguir ou abster-se de determinada atitude. Além de atuar diretamente sobre os indivíduos, essas dimensões interagem mutuamente umas sobre as outras. Um exemplo é a campanha de combate ao fumo, que utiliza a força da lei para impor figuras que desestimulam o tabagismo nas caixas de cigarros, criando assim uma força valorativa. Limites legais também são impostos aos níveis de tabaco e nicotina de modo a evitar um vício químico, vetor fático.

[13] Para o presente estudo, utiliza-se a expressão "rede social verdadeira" como referência àquela que se vale dos dados pessoais e verdadeiros dos seus usuários para permitir a interação através de afinidade de interesses e relacionamentos já existentes no mundo material. Essas redes buscam, contratual e tecnologicamente, evitar que informações falsas ou parciais sejam alimentadas ao sistema, pois causam ruído e prejudicam sua operação otimizada. É, porém, tecnicamente possível a existência de outros modelos de redes sociais que utilizam como base primordial as personalidades fictícias, como aquelas destinadas a role playing games como o Multi-User Dungeon. Redes sociais voltadas a relacionamentos amorosos, por sua vez, estimulam uma combinação: utiliza-se o heterônimo para o contato inicial, que assegura uma maior privacidade e somente em um segundo momento o homônimo é revelado conforme os usuários julguem conveniente. A distinção entre "verdadeiro" e "falso", porém, é controversa, sendo utilizada neste estudo de modo vulgar, sem qualquer reflexão filosófica.

[14] On the Internet, nobody knows you are a dog", legenda de uma charge que ilustrava dois cães conversando na frente de um computador. Publicada por Peter Steiner. The New Yorker. 1993 Jul. 05.

[15] Por exemplo, alguns estúdios de cinema vêm experimentando estratégias de divulgação pela criação de perfis de personagens de seus filmes em redes sociais.Vide mais em Daniel Terdiman. Friendster's Fakester Buddies. Wired News. Disponível em: http://www.wired.com/news/culture/ $0,1284,64156,00 . \mathrm{html}$ ?tw=newsletter_topstories_html.
} 
rede social verdadeira, além das forças éticas, jurídicas e mercadológicas, é necessária a construção de uma arquitetura tecnológica de comunicação que possibilite maior controle aos usuários.

Essa escolha tecnológica deve estudar que efeitos são obtidos através da infra-estrutura e da interface do serviço oferecido. llustra essa relação a preocupação quanto à interface a discussão acerca de controle de recebimento de emails publicitários: dependendo do padrão utilizado no preenchimento de um cadastro, existe maior tendência dos usuários a aceitarem ou rejeitarem a oferta de envio de mensagens publicitárias em seu email. Durante as discussões sobre a regulação (tanto a auto-regulação como a regulação jurídica) houve defensores para um padrão em que para que o usuário recebesse as mensagens de marketing direto, ele deveria necessariamente clicar em uma checkbox confirmando sua aceitação. Essa alternativa resulta em menos aceitações do que a inversa: pressupor a aceitação do usuário, que deve clicar na checkbox para não receber as mensagens. Cada uma das alternativas representa um valor diferente quanto à facilidade ou dificuldade da manifestação de vontade do usuário em controlar o recebimento de mensagens.

Adicionalmente, a tecnologia tem papel fundamental no processo de virtualização que dificulta a percepção dos indivíduos em saber se estão em um ambiente público ou privado e portanto determinar como moderar sua exposição e expectativa de privacidade: Bellotti ${ }^{6}$, analisando a arquitetura de comunicação, aponta dois fenômenos que influem no controle de fluxo de informações, e, portanto, no gerenciamento de privacidade: desincorporação e dissociação (p.74).

Desincorporação ocorre quando os recursos de comunicação não permitem que a apresentação pessoal seja tão efetiva quanto em um ambiente cara a cara. A representação em uma chat room pode ser limitada apenas a palavras, smileys e eventual foto estática $^{8}$ do avatar. A desincorporação também significa que o comunicante pode estar inconsciente acerca da quantidade de informações que está transmitindo publicamente, por uma falta de feedback da arquitetura de comunicação. Alguns sistemas de rede social permitem que o usuário tenha um controle ex post de quem obtém suas informações, valendose de um registro de todos os usuários que obtiveram acesso ao seu perfil. Outros, mais zelosos com a necessidade de controle, usam políticas ex ante de modo que apenas revelam informações pessoais a outros usuários do sistema mediante prévia e expressa autorização do indivíduo. Outros, ainda, revelam qualquer informação a qualquer usuário, sem manter qualquer registro (ou apenas quanto ao número de usuários que obteve acesso a seu perfil) ou selecionam algumas informações que têm caráter mais sensível apenas a determinados grupos de pessoas - sendo, assim, necessário que os usuários classifiquem seus contatos em diferentes categorias, conforme o grau de intimidade ou círculo social a que fazem parte, dependendo, portanto, de uma rotulagem que pode ser aproximada ou refinada conforme a tecnologia adotada. Um dos efeitos da desincorporação é uma maior tendência à bisbilhotagem quando a estrutura de comunicação permite que eu observe o comportamento alheio sem ser observado.

Dissociação é identificada quando uma pessoa remota não possui qualquer presença detectável. Os resultados das ações são compartilhados mas os atores em si são invisíveis ou os atos não são atribuíveis a determinado ator. Não se pode determinar quem está fazendo determinada ação ou quem fez o quê. Assim, pela dissociação as pessoas remotamente conectadas e suas respectivas ações são difíceis de detectar ou identificar. A possibilidade de completa dissociação é relativa quando usadas técnicas de computer forensics e investigação. Entretanto, para a maior parte dos usuários, a escolha entre um ou outro padrão tecnológico influencia no grau de dissociação.

Tanto a desincorporação como a dissociação podem ser reduzidas através da implementação de um retorno maior sobre as informações pessoais que são capturadas e projetadas por usuários da rede social. Os usuários devem dispor de meios técnicos para controlar suas informações pessoais. Bellotti ${ }^{10}$ aponta alguns princípios a serem seguidos e boas práticas necessárias para resgatar a consciência que pode ser perdida na virtualização: podemos não mais saber que tipo de informação estamos transmitido, como ela se parece, quão permanente ela é, a quem é transmitida e quais podem ser os limites daqueles que pretendem utilizá-la.

Paralelamente à decisão sobre a base tecnológica que orientará os limites fáticos sobre $o$ que se pode ou não fazer em uma rede social, é 
necessário refletir sobre aspectos mercadológicos, éticos, e sobretudo jurídicos na elaboração das políticas de uso da rede social.

A título exemplificativo, tomemos o famoso acrônimo YOYOW, que representava os mais fundamentais valores da WELL: "You own your own words"32. Através de mecanismo contratual, os usuários assumem a responsabilidade jurídica ${ }^{[16]} \mathrm{e}$ ética pelos seus escritos e pelas imagens e arquivos disponibilizados através dos serviços de uma rede social. Os usuários são responsáveis em respeitar direitos de terceiros, incluindo os de propriedade intelectual, privacidade, de não caluniar outros membros, enfim, de comportar-se de acordo com padrões éticos e legais. Outro efeito da política YOYOW é que todo o conteúdo publicado pela WELL continua a ser direito patrimonial de seus autores, a não ser na hipótese de sua expressa renúncia. Assim, aceitando a propriedade pelas próprias palavras, seus interlocutores são impactados pela maior responsabilidade quanto às suas conseqüências. Ainda, o usuário tem o direito de remover seus trabalhos da WELL a qualquer tempo.

Essa propriedade contratual assegurada pela rede social decerto não se sobrepõe à liberdade de expressão e aos limites do direito autoral, de modo que continua sendo possível, dentro do razoável, fazer citação de comentários publicados em um fórum da WELL independentemente da autorização prévia do seu locutor ${ }^{33}$ (p.248). Entretanto, o oposto não é necessariamente verdadeiro: se, ao invés da política YOYOW, a rede social contratualmente retivesse para si, com exclusividade, todos os direitos sobre todas as formas de expressão manifestas através de seu sistema, seria juridicamente impossível utilizar qualquer material que tenha ali sido publicado sem uma licença prévia dos representantes legais da rede social.

Ademais ${ }^{[17]}$, essa hipotética política daria à rede social a capacidade jurídica (que, por sua vez, legitimaria a implementação de mecanismo para a possibilidade técnica) de restaurar qualquer conteúdo ali publicado, de modo a preservar o trabalho coletivo. Essa alternativa desperta, por um lado, legítimas preocupações quanto ao direito moral de autor de retirada de circulação previsto no artigo 24 , VI, da Lei de Direitos Autorais, Lei 9.610, de 19.02.1998. Se, por outro lado, não existe qualquer garantia de que as contribuições em discussões de fóruns não serão apagadas pelos usuários, é possível deparar-se com tamanho suicídio digital ${ }^{[18]}$ coletivo que torne sua leitura incompreensível23. Uma abordagem tecnológica para o problema de corrupção do conteúdo é o self-help que mantém um histórico de tudo o que fora anteriormente publicado, possibilitando a restauração, como um wiki.

Reconhecidas as forças tecnológica e jurídica ${ }^{[19]}$ é necessário combiná-las de forma harmoniosa para efetivar os valores buscados pela rede social ${ }^{14}$.

\section{O equilíbrio da privacidade}

Apesar de árdua, a definição de privacidade é necessária para que o Direito possa lidar com violações identificadas. Etimologicamente, privacidade significa privar, separar, alusão ao distanciamento das coisas públicas. Em termos práticos, não é o "direito de ser deixado em paz ${ }^{[20]}$ nem tampouco o "direito a uma personalidade inviolável ${ }^{[21]}$, mas, na definição apropriada do advogado norte-americano Walker ${ }^{31}$, a capacidade de evitar que terceiros utilizem, armazenem, compartilhem informações sobre o

\footnotetext{
[16] Será oportunamente analisado que a limitação de responsabilidade através de instrumento particular é relativa no direito brasileiro.

${ }^{[17]}$ Inúmeros outros questionamentos relacionados à propriedade intelectual podem ser apresentados, como os conflitos que podem surgir entre a política de uso da rede social e eventuais acordos firmados entre empregado e empregador em que a produção intelectual do primeiro é transferida ao último, limites ao fair use, os debates em torno dos hate sites... A intenção deste estudo é discutir apenas alguns dos aspectos jurídicos das redes sociais para despertar a atenção para a importância da harmonização entre as normas jurídicas legais e contratuais com a tecnologia e valores sociais de modo a minimizar os riscos jurídicos de operação e uso de uma rede social.

[18] Blair Newman, após vários anos de participação online com demais colegas da WELL, decidiu apagar todos os seus comentários escritos na rede. Sua atitude despertou indagações a respeito do trauma gerado por uma rasura em massa, como um suicídio intelectual, que precedeu seu suicídio físico semanas depois. O suicídio virtual de Blair foi facilitado por um software disponibilizado por um dos técnicos da WELL que passou a ser utilizado com tamanha freqüência em alguns fóruns "faltava tanta coisa que se tornou desesperadamente impossível seguir o fio à meada", conforme relata Howard Rheingold em "A comunidade virtual"23.

${ }^{[19]}$ Os valores éticos e sociais e as forças de mercado apontados por Lessig em "Code and other laws of cyberspace"14 não são abordados neste estudo. [20] The right to be let alone" é expressão que ficou popular no caso Olmstead v. United States, 277 U.S. 438,478 (1928).

[21] The right to an inviolate personality", expressão usada por Louis Brandeis e Samuel Warren em "The right to privacy", artigo publicado na Harvard Law Review em 1890.
} 
indivíduo. Westin, por sua vez, define a privacidade de informação como "o direito de indivíduos, grupos ou instituições para determinar por si quando, como e em que proporção uma informação a seu respeito é comunicada a terceiros".

O controle sobre a informação pessoal é o controle sobre a personalidade projetada ao mundo, de modo que o direito à privacidade é a liberdade contra limitações arrazoadas em relação à construção da sua identidade (p.7) ${ }^{2}$.

A privacidade pode ser definida como a capacidade de determinar o que o indivíduo deseja revelar e o quanto quer ser acessível (p.89) ${ }^{6}$. Utilizar esse conceito para a elaboração de norma acaba sendo difícil pois para isso dependerá do caso concreto, em que fatores como o grau de intimidade entre os envolvidos, o ambiente onde os relacionamentos ocorrem, as expectativas de cada um, entre outros, estão envolvidos.

Fica claro que a privacidade não é um conceito unitário. Solove ${ }^{29}$ argumenta que a privacidade não pode ser adequadamente definida pelo isolamento de um denominador comum em todas as miríades situações que entendemos haver uma violação da privacidade. Ele sugere um conceito bottom-up que focalize determinados problemas relacionados mas que não necessariamente partilham de um elemento comum. Existem muitos tipos de problemas de privacidade que, apesar de relacionados, distinguem-se significantemente.

A percepção de privacidade em determinado sistema jurídico em determinado momento histórico deve servir como base para controle de riscos legais que os sistemas de redes sociais enfrentam e das possibilidades de manifestação que os usuários possuem com amparo legal. Assim, deve ser decidido se as informações são livre e espontaneamente disponibilizadas a todos, indistintamente de ser seu observador um usuário credenciado ou não, ou somente a usuários que tenham intimidade em determinado círculo social.

Faz-se também necessária a identificação de encarar a privacidade de forma objetiva ou subjetiva. Se somente houver violação da esfera da intimidade a partir do momento que um outro ser humano tem acesso a informações sensíveis, como opção religiosa, sexualidade, histórico de doenças, um sistema de inteligência artificial que receba tais informações, e esteja programado a não divulgá-las de modo algum, utilizando-as apenas com propósitos de levantamentos estatísticos, não infringiria a privacidade, de acordo com esta definição.

De qualquer forma, na busca de definições e respostas a indagações sobre a natureza jurídica da privacidade, é necessário aceitar que, assim como a noção de subjetividade, ela varia conforme o momento histórico vivido e, assim, não é apropriado que a lei engesse seu conceito. Entendida a privacidade como relacionada à informação que está disponível a respeito de uma pessoa, deve-se reconhecer que, na sociedade da informação, existe tendência a uma maior dificuldade em controlar e identificar o que é público e privado.

Apesar da inexistência de diploma específico sobre o tema, a proteção da privacidade é garantida pela Constituição Federal de 1988 ("CF88") e legislação esparsa sobre o assunto. O Art. $5^{\circ}, \mathrm{X}$, da CF88 diz que "são invioláveis a intimidade, a vida privada, a honra e a imagem das pessoas, assegurado o direito à indenização pelo dano material ou moral decorrente de sua violação". Assim, a intimidade configura-se, pela redação constitucional, distinta do conceito de vida privada, honra e imagem das pessoas. Como esclarece Silva ${ }^{28}$, a terminologia não é precisa e assim seu "Curso de direito constitucional positivo" adota a expressão "direito à privacidade" em um sentido genérico e amplo.

Comentando o mesmo dispositivo constitucional, Bastos $^{5}$ afirma compreender a faculdade individual de obstar a intromissão de estranhos em sua vida privada e familiar e de impedir o acesso a informações sobre a privacidade de cada um e de evitar que sejam divulgadas informações sobre esta área da manifestação existencial do ser humano (p.63).

A proteção à privacidade é considerada tanto um direito fundamental como um direito da personalidade. São direitos de mesma essência, mas conforme Jabur ${ }^{11}$, o primeiro é uma proteção do indivíduo contra o arbítrio do Estado e o último pertence ao direito privado, direcionado às relações entre particulares.

Uma solução de arquitetura é proposta por Lessig ${ }^{14}$ para os problemas de privacidade com base em duas premissas: 1) conferir a cada indivíduo um 
direito proprietário sobre suas informações pessoais; e 2) empregar protocolos de transmissão como o Privacy Preferences Project (P3P) ${ }^{[22]}$ que permite ao usuário controlar seu acesso a websites dependendo de suas preferências pré-estabelecidas de privacidade, de modo que, por exemplo, descontos em preços de mercadorias pudessem ser concedidos caso o usuário decidisse divulgar maiores informações pessoais.

A discussão que se coloca em torno do P3P e da solução de Lessig merece análise quanto ao caráter irrenunciável da privacidade enquanto direito fundamental. Caso prevaleça o entendimento de ser completamente irrenunciável, a negociação sugerida por Lessig seria nula e portanto permaneceria o website sujeito à responsabilidade caso posteriormente o usuário, sentindo-se violado em sua privacidade por uma transação realizada, decida processá-lo. Os riscos ficam ainda mais agravados considerando-se a imprescritibilidade desse direito ${ }^{26[23]}$.

Em 1980, a Organização para Cooperação Econômica e Desenvolvimento - OECD estabeleceu linhas mestras de proteção à privacidade ${ }^{17}$. Quanto ao Princípio da Participação Individual defendido pela OECD, que busca fornecer ao indivíduo o poder de obter a confirmação se dados a seu respeito estão inseridos em determinado banco de dados, de modo satisfatório, bem como providenciar sua retificação, merece destaque o instituto do habeas data previsto no artigo $5^{\circ}$, LXXII, da CF88 e regulado pela Lei $n^{\circ}$ 9.507, de 12.11.1997.

Ainda no campo de princípios gerais sobre tratamento legal da privacidade, é válido comentar também a nova disposição legal implementada no artigo 21 do Código Civil, que estabelece que a vida privada da pessoa natural é inviolável, e o juiz, a requerimento do interessado, adotará as providências necessárias para impedir ou fazer cessar ato contrário a esta norma.
São, assim, diversos os recursos jurídicos e técnicos para o controle da privacidade. Apesar do interesse dos indivíduos em controlar a informação que chega a eles, manifesta por exemplo nos casos do telemarketing e do spam, existe um valor das informações compartilhadas em sociedade que pode ser perdido no caso de controle total[ ${ }^{[2]}$. A economia capitalista e a sociedade livre dependem de trocas de informações independentemente de prévia solicitação, como campanhas eleitorais, anúncios em outdoors, passeatas... os quais devem respeitar limites pré-estabelecidos. Um equilíbrio pode ser atingido a partir do momento inicial em que é facultado receber informações adicionais conforme interesse do indivíduo.

Os benefícios da troca de informação, como diminuição de preços pela redução dos custos de transação a partir de um mercado mais transparente (p.20) ${ }^{16}$, são analisados por Walker ${ }^{31}$, que aponta, entre outros, para ampliação de acesso de informações e conveniência do atendimento customizado. Conforme informações pessoais são disponibilizadas o senso comunitário também é fortalecido, possibilitando assim a formação de elos de afinidade por intermédio de sistemas de comunicação telemáticos sem que a localização geográfica seja um ponto de partida ou uma coerção (p.20) ${ }^{15}$. A segurança é também aperfeiçoada pela maior confiabilidade das informações: números seriais de identificação em hardware e software podem ser utilizados para saber de onde vieram ataques a sistemas protegidos, e mesmo criação de vírus, como ocorreu no caso do autor do vírus Melissa (p.20) ${ }^{31}$.

A anonímia, em situações como essa, desestabilizaria a responsabilidade social e jurídica que pode ser atribuída em atos repreensíveis. A anonímia pode ter papel de importância no contexto de sistemas políticos repressores em que a liberdade de expressão não poderia de outra forma ser

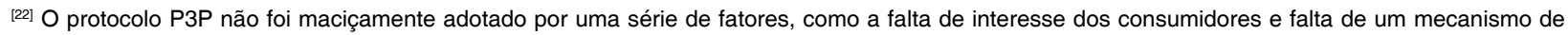
marketing para incentivar sua implementação e uso. Entretanto, continua sendo uma alternativa técnica para lidar com a privacidade na Internet.

[23] Quanto a questionamentos sobre a eficácia das criativas propostas de Lessig, é válida a consulta a "Beyond Lessig's code for internet privacy: cyberspace filters, privacy-control, and fair information practices", de Paul Schwartz.

${ }^{[24]}$ Esse excesso de controle é um fenômeno descrito como oversteer por Andrew Shapiro em "The control revolution: how the internet is putting individuals in charge and dhanging the world we know”. Basicamente, Shapiro alerta para os riscos que existem no controle absoluto das informações, que diminui os encontros aleatórios necessários para uma experiência comum, uma cola social, entre os cidadãos de uma democracia. Essa teoria é posteriormente desenvolvida por Cass Sunstein, em Republic.com.
} 
exercida, sob risco de retaliação. Mas, em situações ordenadas, não é um valor a ser defendido, de modo que o anonimato é vedado pela CF88, em seu artigo $5^{\circ}$, IV. A vedação constitucional busca assim, atribuir responsabilidade àqueles que exercem a liberdade de pensamento evitando os abusos que podem decorrer da impunidade facilitada pela ocultação. Os excessos devem ser sempre evitados: a demasiada preocupação com a privacidade, expressa na forma de normas rígidas, pode fazer com que outros valores sejam perdidos. A regulação apressada e sem reflexão pode causar o término de uma série de atividades empreendedoras legítimas e inovadoras, e também prejudicar o livre fluxo de informações necessário para a promoção de objetivos individuais, comunitários e sociais.

Como já observado, as tecnologias trazem aspectos tanto positivos como negativos. A atitude da sociedade perante assuntos de privacidade muda, conforme novas tecnologias apresentam benefícios, como a filmagem de ruas. A maior exposição das pessoas em ambientes públicos perante autoridades imperceptíveis contribui para a melhora na prestação de serviços públicos, especialmente quanto à redução da criminalidade ${ }^{[25] 18}$. Além do peso imediato a ser suportado pela implantação desses sistemas, o que deve ser feito é uma análise dos danos que podem ocorrer caso o sistema seja violado por terceiros de má-fé ou saia de controle.

As reflexões sobre a natureza jurídica da privacidade são necessárias para a sua proteção. A identificação do momento de sua violação é um dos pontos que requer maior definição: quando ocorre? No momento da coleta não autorizada? Quando um terceiro não autorizado obtém acesso aos dados? No processamento dos dados? Quando os resultados dos dados processados são publicados? Quando atitudes baseadas nos dados processados e publicados são tomadas?

Semelhantes questionamentos foram levantados pelo grupo de trabalho convocado pela OMPI para tratar da proteção dos bancos de dados: na ausência de uma autorização expressa por parte do titular do direito de autor, constituiria o aproveitamento de sua obra violação ao direito de autor ou somente a saída é que a caracterizaria? Antônio Chaves relata que fora concluído "que a entrada (incluída a fixação na memória interna de um computador) deveria ser considerada uma reprodução, tanto mais que a saída não implica necessariamente em qualquer violação ao direito de autor e que a autorização necessária deveria ser solicitada por ocasião da entrada". Podese fazer uma analogia com relação ao momento em que pode ocorrer uma violação aos direitos de privacidade quando ocorre a mera inclusão dos dados em um sistema?

Nesse sentido, é necessário um alerta contra o Tecnopólio descrito por Postman ${ }^{21}$. A dependência excessiva das técnicas de estatística e mapeamento de perfil pode acabar rotulando os usuários a ponto de diminuir sua exposição a determinados conteúdos que o sistema de banco de dados entenda que não são de interesse pelo perfil analisado. Essa excessiva rotulagem diminuiria a liberdade dos cidadãos ${ }^{[26]}$.

\section{CONCLUSÕES}

Existem novos conflitos trazidos pelas redes sociais, especialmente aqueles ligados à privacidade e à difusão de informações pelos diversos círculos sociais simultaneamente. As redes sociais apresentam novas formas de interação social e um questionamento sobre os limites legais, contratuais e tecnológicos para a sua utilização. Pela sua natureza de rede, conforme maior sua utilização, maior poder possui para a atração de novos usuários, influenciando na análise de custo e benefício de estar ou não cadastrado a um sistema de rede social.

A proteção a bancos de dados diferencia-se da proteção conferida à privacidade. Entretanto, sua regulação jurídica é difícil por existir uma pluralidade de concepções acerca dos espaços públicos e privados, uma diferente valoração de custo e benefício dos usuários de redes sociais, que se transforma em uma colaboração dos próprios indivíduos para uma maior exposição de sua vida particular a público.

[25] A reportagem "Olhos por toda parte"18 publicada na Revista Veja, relata a experiência de monitoramento por câmeras instaladas nas ruas de Londres, Nova York, Washington, Paris, Berlim, Joinville, Recife, Suzano, Belo Horizonte e Curitiba. Quanto à capital do Estado do Paraná, reporta que "houve protestos por parte da população assim que as filmadoras foram implantadas. Mas, com o passar do tempo, as pessoas se acostumaram com a presença delas."

[26] O estudo promovido por Lada Adamic, Orkut Buyukkokten, e Eytan Adar, A Social Network Caught in the Web, disponível em: <http://www.firstmonday.dk/ issues/issue8_6/adamic/>, já traçava determinadas regras de fundamentalismo de acordo com a análise do Club Nexus. 
A liberdade de escolha é um valor que deve ser preservado, entretanto evitando a comoditização da privacidade, caso entendida como um valor constitucional indisponível.

A lei não deve impor concepções sobre o que é público e o que é privado, mas sim oferecer mecanismos para aqueles que desejam proteger sua esfera íntima e fornecer meios de reparação caso essa seja devassada. Sendo ferramentas que permitem violações de proporções antes desconhecidas, as redes sociais devem estar atentas e responsáveis para orientar seus usuários sobre os riscos envolvidos e providenciar mecanismos tecnológicos e contratuais buscando a máxima proteção e menor oportunidade de realização de práticas abusivas através de seus sistemas. Os riscos apresentados diante da operação de redes sociais são consideráveis, dada a subjetividade do conceito de privacidade. Para bem gerenciar os riscos do negócio, a tecnologia do sistema de rede social deve possibilitar tornar privada determinada informação a determinado grupo de pessoas ou a um grupo indistinto. Assim, combinar tecnologia e direito é essencial. Para isso, os termos de uso e políticas de privacidade são importantes, devendo-se ressaltar que o direito brasileiro não aceita negociação particular sobre provisões de matéria pública e cogente, existindo limitação à liberdade contratual que deve ser considerada.

A construção colaborativa da regulação das redes sociais inclui os usuários, desenvolvedores destes sistemas, e, principalmente, legisladores que estabelecerão limites legais mínimos para atingir um equilíbrio apropriado e saudável entre o público e o privado.

Arata Jr S. The new challenges to privacy: social networks. Saúde, Ética \& Justiça, São Paulo. 2003;8(1/2):4456.

ABSTRACT: Internet social network services have drawn attention and enthusiasm from the Brazilian market in 2004. In this article some reflections on the legal aspects of the relationship between technological structure and terms of use implemented. The notion of privacy has historically been developed according to the development of new technologies which menace previous expectations of social relationship of individuals, and the technologic, ethic and legal responses used. Electronic social networks allow an unforeseen integration of social circles, making difficult the use of social masks and separation of information inside certain contexts. In some situations this may imply in a menace to intimacy, which shall be dealt with using technical and legal approaches. Regardless of the choice made, it is important to bear in mind the subjectivity of the notion of truth, privacy, intimacy. That the solutions shall not hold still or impose arbitrary standards, but, on the other hand, allow a flexible menu of choice for those who intend to keep a higher seclusion of personal information and at the same time create structures that allow those who want to establish a broader communication, to do so through secure media.

KEY WORDS: Privacy. Technology reliability.

\section{REFERÊNCIAS}

1. $\quad$ Agre P. Beyond the mirror world. In: Agre $P$, Rotemberg $M$, org. Tecnhology and privacy: the new landscape. London: The MIT Press; 1998.

2. Agre $P$, Rotemberg $M$, org. Tecnhology and privacy: the new landscape. London: The MIT Press, 1998.

3. Arendt H. A condição humana. 10a ed. Rio de Janeiro: Forense Universitária; 2004.

4. Bastos $C R$, Martins IG. Comentários à constituição do Brasil: promulgada em 5 de outubro de 1988. São Paulo: Saraiva; 1989.

5. Bastos CR. Curso de direito constitucional. v.2, p.63.
6. Bellotti V. Design for privacy in multimedia computing and communications environments. In: Agre P, Rotemberg M, org. Tecnhology and privacy: the new landscape. p.74.

7. Comparato FK. A afirmação histórica dos direitos humanos. 3a ed. São Paulo: Saraiva; 2003.

8. Donath J. Sobre a importância do contato visual com o rosto em interações mediadas por sistemas de comunicação [Mediated faces]. Disponível em: http:/ /smg.media.mit.edu/papers/Donath/MediatedFaces/ MediatedFaces.CT2001.pdf

9. Golbeck J. Reputation network analysis for email 
filtering. Disponível em: http://www.mindswap.org/ papers/Email04.pdf.

10. Heymann P. Distributed social network protocol. Disponível em: http://www.cs.duke.edu/ pbh/ downloads/dsnp-paper.pdf.

11. Jabur GH. Liberdade de pensamento e direito à vida privada. São Paulo: RT; 2000.

12. Kundera M. A insustentável leveza do ser. Trad. Teresa Bulhões Carvalho da Fonseca. São Paulo: Companhia das Letras; 1999.

13. Kundera M. Testaments betrayed; ans essay in nine parts. London: Faber; 1995.

14. Lessig L. Code and other laws of cyberspace. New York: Basic Books; 1999.

15. Levy P. O que é virtual? São Paulo: Ed. 34; 1996.

16. OECD - Organisation for Economic Co-operation and Development. Disponível em: http:// w w w. o e c d . org/d o c u m e n t / $18 /$ 0,2340,en_2649_34255_1815186_1_1_1_1,00.html.

17. Olhos por toda a parte. Rev Veja, São Paulo. 2004 ago. 4;ed. 1865;37(31).

18. Pescovitz D. The technology or the year: social network applications. Business 2.0, San Francisco. 2003;4(10):113.

19. Pontes de Miranda. Tratado de direito de família. 3a ed. São Paulo: Max Limonad; 1947.

20. Reale M. Teoria tridimensional do direito. São Paulo: Editora Saraiva; 1968.

21. Rheingold H. A comunidade virtual. Lisboa: Gradiva; 1996.
22. Scherer-Warren II. Redes de movimentos sociais. São Paulo: Edições Loyola; 1993.

23. Schwartz PM. Beyond lessig's code for internet privacy: cyberspace filters, privacy-control, and fair information practices. Disponível em: http:// www.paulschwartz.net/pdf/Schwartz_final.pdf.

24. Shapiro $A$. The control revolution: how the internet is putting individuals in charge and changing the world we know. New York: Public Affairs; 1999.

25. Shirky C. Social software and the politics of groups. Disponível em: http://www.shirky.com/writings/ group_politics.html.

26. Silva JA. Curso de direito constitucional positivo. 12a ed. São Paulo: Malheiros Editores; 1996.

27. Solove DJ. Conceptualizing privacy. Disponível em: http://law.shu.edu/faculty/fulltime_faculty/soloveda/ concept_privacy.pdf.

28. Technorealism overview. Disponível em: http:// www.technorealism.org.

29. Walker K. Where everybody knows your name: a pragmatic look at the costs of privacy and the benefits of information exchange. Stanford Technol Law Rev. Disponível em: http://stlr.stanford.edu/STLR/Articles/ 00_STLR_2.

30. The Well. Agreement. Disponível em: www.well.com/ member_agreement.html.

31. Whittle D. Cyberspace: the human dimension. New York: W. H. Freeman and Company; 1997.

32. WSIS: World Summit on the Information Society. Disponível em: http://www.itu.int/wsis. 